\title{
Delusion of Pregnancy in a 60 Years Old Lady
}

\author{
Madhurima Khasnobis, Prosenjit Ghosh*, Hasina Anjuman Choudhury
}

Department of Psychiatry, Silchar Medical College, Silchar, India

Email address:

p_ghosh72@yahoo.com (P. Ghosh)

${ }^{*}$ Corresponding author

\section{To cite this article:}

Madhurima Khasnobis, Prosenjit Ghosh, Hasina Anjuman Choudhury. Delusion of Pregnancy in a 60 Years Old Lady. American Journal of Psychiatry and Neuroscience. Vol. 7, No. 2, 2019, pp. 30-32. doi: 10.11648/j.ajpn.20190702.11

Received: May 7, 2019; Accepted: June 6, 2019; Published: June 20, 2019

\begin{abstract}
BACKGROUND-The delusion of pregnancy is a condition where the person strongly believes that he/she is pregnant in spite of providing enough evidence to the contrary. Though previously it was considered rare, the number of such cases are gradually increasing in developing countries but the literature regarding this is very meagre in India particularly in the North-East. METHOD - In this article we report the unique case of a 60yrs old woman from rural Assam who developed delusion of pregnancy following her menopause thirteen years back, which has been continuing ever since. RESULT- A 60ys old woman presented in the OPD of Tertiary Care Hospital with feelings of movement of foetus in her womb. This was also associated with tremulousness of whole body, burning sensation of both lower limbs, palpitation, irritability and disturbed sleep for $13 y r s$ with episodic exacerbation currently increased for 4-5months. She was a housewife, completed her family and lived with her husband and three children. She was apparently well $13 y$ rs back when following her menopause at age 42 yrs she started to doubt if she is pregnant or not. Multiple gynaecologists' opinion was taken but that did not convince her and she continued to believe she was pregnant and felt the movement of the baby inside her womb. CONCLUSION - Although these kinds of patient visit the obstetrician first but historically and clinically this type of delusion of pregnancy is clearly different from the phenomenon of pseudocyesis. Hence treatment approach of both are also different. We need further research to explore this rarely reported phenomenon.
\end{abstract}

Keywords: Delusion, Delusion of Pregnancy, Pseudocyesis, Elderly Woman, Postmenopausal, Shrunken Foetus, Antipsychotics

\section{Introduction}

Manjunatha et al [1] in his study has introduced a new concept of psychopathology related to human procreation and referred to it as Delusional Procreational Syndrome (DPS). It includes delusion in every stage of procreation be it having a spouse, getting pregnant, delivery of the baby (labour and childbirth) and so on. These are termed as 'selfreferential' delusions where patient himself is a part of the delusion complex [1-3]. Among these DPS one of the most commonly reported cases are that of delusion of pregnancy $[4,8]$. It is found commonly in males, can also occur in postmenopausal as well as virgin woman [13], lasting up to almost 20yrs [14], involving at times multiple other delusions [10]. Our case highlights the prevalence of delusion of pregnancy in an elderly woman in absence of any underlying psychotic depressive illness or any major physical comorbidity like dementia, delirium [19-23].

\section{Case}

A 60ys old woman, illiterate, hailing from lower middle class socio economic background from rural residency of NE part of India presented in the OPD of Tertiary Care Hospital with feelings of movement of foetus in her womb. This was also associated with tremulousness of whole body, burning sensation of both lower limbs, palpitation, irritability and disturbed sleep for 13yrs with episodic exacerbation currently increased for 4-5months. She is a housewife and lives wither her husband and 3 children with a history of a mutually decided MTP 1yr prior to the birth of her youngest child, who is currently 18 yrs old. She was apparently well $13 \mathrm{yrs}$ back. At the age of $42 \mathrm{yrs}$, her menstruation ceased and she started to doubt if she is pregnant or not. At that time 
gynaecologist opinion was taken, a urine pregnancy test was done which came out to be negative. But however it did not convince her and she continued to believe she was pregnant and felt the movement of the baby inside her womb. She was taken to a local physician for her somatic complaint and she was prescribed some medicines on taking which her bodily symptoms subsided. On repeated suggestions by family members, by 4-5 months she started to doubt about her pregnancy. She started to feel its diminished movements and also noticed that there was no increase in size of her abdomen.

Though the problem stopped, it was only temporarily. Every year, she could feel the movement of the foetus in lower abdomen below the level of the umbilicus, which lasted for a few days and then stopped. But at no point in this $13 y r s$ was she fully convinced about her non pregnant state. One year before visiting psychiatric OPD, she had extensive fungal infection in her inner thigh, and was often seen collecting her urine in a pot and fondling with it, when asked she used to say that there were germs of size of sand particles which came out through her urine, and often expressed her thoughts that the dead rotten foetus in her womb may be the source of the germ. About 4-5 months from now, her discomfort increased several folds. She again started feeling the movement of her foetus, which according to her is about the size of a tennis ball moving from left iliac fossa to the right one. The movement was associated with severe bodily discomfort like palpitation, heaviness and burning sensation of limbs, nausea, increased frequency of micturition and she related these changes similar to the physical changes of a pregnant woman. She felt the movement almost every day, with increased frequency at night and whenever she tried to control it by pressing one side of abdomen, it shifted to the opposite side. She was taken to a gynaecologist again and subsequently referred to the psychiatry dept. where she was examined in details for her condition.

A detailed physical and mental state examination was done. She was of ectomorphic built, well groomed, adequate eye contact, and normal psychomotor activity. Rapport was established, mood was anxious, affect was appropriate, stable, reactive, moderate intensity and restricted towards the anxious side. Speech was otherwise relevant, coherent with normal reaction time. Thought content revealed no other abnormality except for a firm and fixed belief of having pregnancy. No formal thought disorder or perceptual disturbances were detected in the interview. All parameters of Higher Mental Function were intact with insight being grade I. She was diagnosed as a case of Delusional Disorder somatic type according to ICD 10 guidelines.

She was started on tab. Olanzapine $(10 \mathrm{mg})$ and lorazepam ( $2 \mathrm{mg}$ ) on a daily basis. She was known hypertensive and was already on Tab. Losartan 50mg once bedtime dose.

\subsection{Laboratory Investigation}

TC, DC, ESR, random blood sugar, urea, creatinine, LFT revealed no abnormality. However, ultrasonography whole abdomen revealed multiple GB calculi with the largest one being $7.1 \mathrm{~mm}$. Her thyroid reports revealed normal results. Other radiological examinations could not be done due to financial constraints.

\subsection{Psychometric Assessment}

Rorschach and TAT Revealed patient was having delusional disorder.

\subsection{On Follow-up}

After 7 days the patient came for follow up. Her somatic symptoms and anxiety had decreased much. She was getting a full $7-8 \mathrm{hrs}$ sleep at night, eating satisfactorily. Though she still believed that the foetus was in her womb but her conviction had decreased. Bhagyashree et al also reported good improvement with antipsychotics in a patient of delusion of pregnancy [24].

\section{Discussion}

Our patient interestingly had no other symptoms of medical or psychiatric illness but a single and wellsystematised delusion of pregnancy which began at the time of her menopause. By definition, delusions are firm, false and unshakable belief that is out of keeping with patient's socio cultural belief.

Clearly, this case has to be differentiated from other conditions mimicking pregnancy;

Pseudocyesis: it falls under the Not Elsewhere Classified section of Somatic Symptom disorders, in DSM-5 [10]. Here a young female, usually of reproductive age group, having extreme desire of conceiving, develops classic symptoms of pregnancy i.e. amenorrhea, nausea, breast enlargement, pigmentation and abdominal distention followed by in some cases even labour pain [5, 11-13].

Couvade syndrome-where the husband of pregnant woman experiences the physiological changes of pregnancy like his wife [15].

Malingering-in which person claims to be pregnant but actually knows that she is not

Pseudo pregnancy-in which ovarian tumours causes endocrinal changes suggestive of pregnancy [16]

Organic brain syndrome that can mimic changes of pregnancy- like sequale of head trauma, encephalitis and many more [17]

In this patient, the delusion developed initially from a misconception with menopause. Further there was cognitive misinterpretation of bodily signs and symptoms with symptoms similar to pregnant state which patient had already experienced while she conceived in true sense. Further illiteracy and low socioeconomic status exacerbated the problem. The patient might not be in a position to accept that she had grown old and attainted menopause but still believed that she is young and capable of childbirth. This might be a common suppressed fear and cultural attitude towards ageing in general among the female population. The role of sociocultural factors in the development of delusion of pregnancy 
has been reported in patients, suggesting that contextual variables may exert influence particularly when pregnancy confers a higher valued social status [25]. Our case also contradicts the common theories that delusion of pregnancy is most commonly associated with schizophrenia, schizoaffective disorder, delusional disorder, mental retardation, drug (antipsychotic) induced lactation [17-23].

\section{Conclusion}

In our study the patient had a completed family with three children and husband and had no undue urge of having any further pregnancy. Although these kinds of patient visit the obstetrician first but historically and clinically this type of delusion of pregnancy is clearly different from the phenomenon of pseudocyesis. Biological and psychological theories offer complementary viewpoints in the genesis of this phenomenon. Hence, while we diagnose such patients, it is important to look for patient's cognitive functioning. To conclude, delusion of pregnancy is a heterogeneous symptom which emerges during the course of various neuropsychiatric syndromes. It occurs not only in women but also occurs in men. The delusion may have many social, psychological and biological determinants to its genesis. Pharmacology remains the mainstay of treatment, antipsychotics play a major role in delusion of pregnancy while psychotherapy and reassurance and ruling out endocrinopathies are mainstay of treatment of pseudocyesis. Still this phenomenon of delusion of pregnancy will require further analysis and investigation to understand it better.

\section{References}

[1] Manjunatha N, Sarma PK, Math SB, Chaturvedi SK. Delusional procreation syndrome: A psychopathology in procreation of human beings. Asian J Psychiatr. 2010; 3: 846.

[2] Manjunatha N, Reddy KS, Renuka Devi NR, Rawat V, Bijjal $\mathrm{S}$, Kumar $\mathrm{CN}$, et al. Delusion of polygamy in proxy: An addition to delusional procreation syndrome. Indian $\mathrm{J}$ Psychiatr. 2011; 53: 266-9.

[3] Viswanath B, Kamath A, Goswami K, Taksal A, Thippeswamy H, Chaturvedi SK. Delusion of paternity. Aust N Z J Psychiatr. 2012; 46: 175.

[4] Manoj PN, John JP, Gandhi A, Kewalramani M, Murthy P, Chaturvedi SK, et al. Delusion of test-tube pregnancy in a sexually abused girl. Psychopathology. 2004; 37: 152-4.

[5] Harland RF, Warner NJ. Delusions of pregnancy in the elderly. Int J Geriatr Psychiatry 1997; 12: 115-7.

[6] Curran GSM, Pugh RE. Delusions of pregnancy and delivery in elderly women. Int J Geriatr Psychiatry 1995; 12: 1075-6.

[7] Camus V, Schmitt L, Foulon C, Lima CA, Wertheimer J. Pregnancy delusions in elderly depressed women: a clinical feature of Cotard's syndrome? Int J Geriatr Psychiatry 1995; 10: $1071-3$
[8] Cipriani G, Di Fiorino M. Delusion of pregnancy: an unusual symptom in the context of dementia. Am J Alzheimer Dis 2015; 30: 341-5.

[9] Patricia Guilfoyle, Helen O'Brien, Shaun T. O'Keeffe, Delusions of pregnancy in older women; a case series, Age and Ageing, Volume 44, Issue 6, November 2015, Pages 10581061 .

[10] American Psychiatric Association. Diagnostic and Statistical Manual of Mental Disorders: DSM-5. Washington, DC: American Psychiatric Association, 2013.

[11] Tarín JJ, Hermenegildo C, García-Pérez MA, Cano A. Endocrinology and physiology of pseudocyesis. Reprod Biol Endocrinol 2013; 11: 1186.

[12] Seeman MV. Pseudocyesis, delusional pregnancy, and psychosis: the birth of a delusion. World J Clin Cases 2014; 2: $338-44$.

[13] Dutta S, Vankar GK. Delusions of pregnancy-a report of four cases. Indian journal of psychiatry. 1996 Oct; 38 (4): 254.

[14] De Pauw KW. Three Thousand Days of Pregnancy: A Case of Monosymptomatic Delusional Pseudocyesis Responding to Pimozide. British Journal of Psychiatry. Cambridge University Press; 1990; 157 (6): 924-8.

[15] Enoch MD, Trethowan SW, BARKER J. The couvade syndrome. Uncommon Psychiatric Syndromes,. 1991: 92-111.

[16] Hardwick PJ, Fitzpatrick C. Fear, folie and phantom pregnancy: pseudocyesis in a fifteen-year-old girl. The British Journal of Psychiatry. 1981 Dec; 139 (6): 558-62.

[17] Chaturvedi SK. Delusions of pregnancy in men: case report and review of the literature. The British Journal of Psychiatry. 1989 May; 154 (5): 716-8.

[18] Cramer B. Delusion of pregnancy in a girl with drug-induced lactation. American Journal of Psychiatry. 1971 Jan; 127 (7): 960-3.

[19] Chengappa KNR, Steingard S, Brar JS, Keshavan MS. Delusions of pregnancy in men. British Journal of Psychiatry. Cambridge University Press; 1989; 155 (3): 422-3.

[20] Shankar R. Delusion of pregnancy in schizophrenia. The British Journal of Psychiatry. 1991 Aug; 159 (2): 285-6.

[21] Bitton G, Thibaut F, Lefevre-Lesage I. Delusions of pregnancy in a man. The American journal of psychiatry. 1991 Jun;148:811-812

[22] Michael A, Joseph A, Pallen A. Delusions of pregnancy. The British Journal of Psychiatry. 1994; 164 (2): 244-6.

[23] Sims A. Symptoms in the mind: An introduction to descriptive psychopathology. Bailliere Tindall Publishers; 1988.

[24] Bhagyashree H. Gaikwad, Amit R. Dharmadhikari, Alka A. Subramanyam, Jahnavi S. Kedare, Ravindra M. Kamath. Delusion of pregnancy in a 70-year-old male. Indian Journal of Psychiatry. 2017; 59 (1):130.

[25] Sagar Chandra Bera, Siddharth Sarkar. Delusion of Pregnancy: A Systematic Review of 84 Cases in the Literature. Indian Journal of Psychological Medicine. 2015; 37 (2): 131-137. 